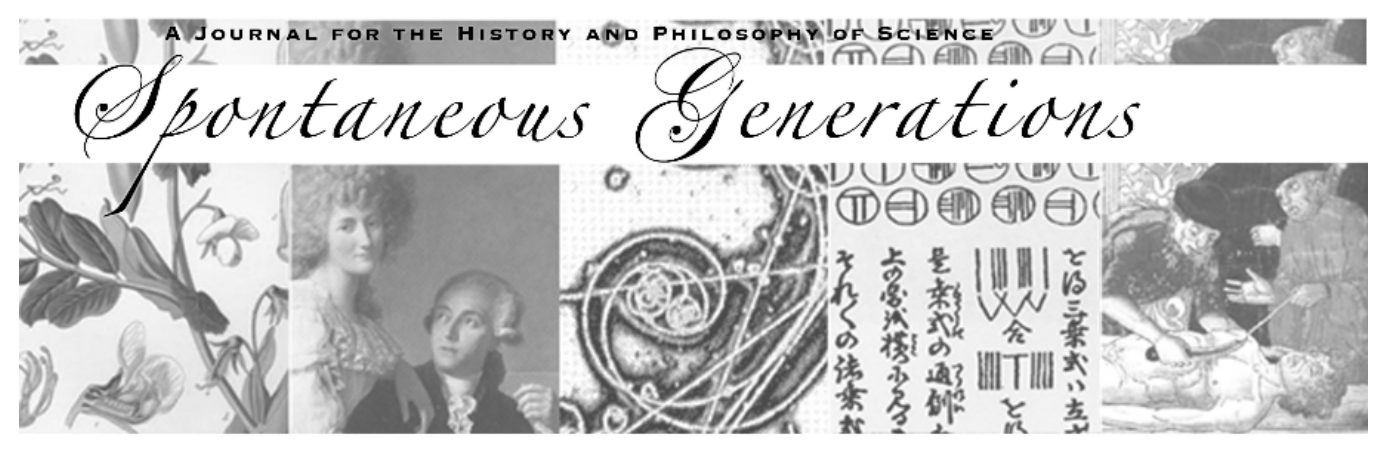

\title{
BEWARE OF Mad DOG Realist
}

Author(s): Alan Musgrave

Source: Spontaneous Generations: A Journal for the History and Philosophy of Science, Vol. 9, No. 1 (2018) 52-64.

Published by: The University of Toronto

DOI: $10.4245 /$ sponge.v9i1.27051

\section{E D I T O R I A L O F F I C E S}

Institute for the History and Philosophy of Science and Technology

Room 316 Victoria College, 91 Charles Street West

Toronto, Ontario, Canada M5S 1K7

hapsat.society@utoronto.ca

Published online at jps.library.utoronto.ca/index.php/SpontaneousGenerations ISSN 19130465

Founded in 2006, Spontaneous Generations is an online academic journal published by graduate students at the Institute for the History and Philosophy of Science and Technology, University of Toronto. There is no subscription or membership fee. Spontaneous Generations provides immediate open access to its content on the principle that making research freely available to the public supports a greater global exchange of knowledge. 


\title{
BEWARE OF Mad DOG Realist*
}

\author{
Alan Musgrave ${ }^{\dagger}$
}

Once, in America, I got into an argument with some local antirealist philosopher, and must have said something outrageous. Whereupon Bill Lycan exclaimed, "Oh, you mad-dog realist you, I love it!" Before I left to come home to New Zealand, my friend Deborah Mayo gave me a Wild West sign as a farewell present. That sign is the title of my paper. Though I am very proud of my sign, it is a little misleading. I am not really a mad-dog realist-more like a lap-dog realist.

If science is to be believed, we are a bunch of middle-sized land mammals. We are not the biggest land mammal on the planet, or the strongest, or the swiftest-but we are the smartest. We are so smart that we can even try to figure out how the planet works. That is called "SCIENCE." And it is one of the great achievements of humanity. The view that science seeks to understand how the world works is called scientific realism. Realism is the obvious, commonsensical view, the instinctive philosophy of most working scientists.

It astonishes me that many people try to rob us of this great achievement, by going in for antirealist views that deny that science can or should seek to understand the world. I have tried to expose this act of intellectual thievery for what it is. There is an old proverb: "Set a thief to catch a thief." It takes a philosopher to catch the antirealist philosophers out.

Trouble arises because realism comes in different versions, some more optimistic than others. Optimistic realists claim that science not only seeks to explain things, but can also know for certain when it has found a true explanation. Even more optimistic realists claim that science can achieve ultimate explanations about which no further explanatory question

* Received July 16, 2016, Accepted July 16, 2016

$\dagger$ Alan Musgrave (b. 1940) has been Professor of Philosophy at the University of Otago (New Zealand) since 1970. He was educated at the London School of Economics, where his PhD was supervised by Sir Karl Popper. With Imre Lakatos he edited Criticism and the Growth of Knowledge (1970), a most influential collection of essays in twentieth century philosophy of science. His other publications include Common Sense, Science and Scepticism (1993), Essays on Realism and Rationalism (1999), and Secular Sermons (2009). His views were the subject of a collection of essays Rationality and Reality: Conversations with Alan Musgrave (2006).

Spontaneous Generations 9:1 (2018) ISSN 1913-0465. University of Toronto.

Copyright 2018 by the HAPSAT Society. Some rights reserved. 
can be asked. This is mad-dog realism proper, the view that science can achieve certainly true and ultimate explanations. Antirealists object to these claims, and throw the realist baby out with the mad-dog realist bathwater. Antirealists rightly point out that a scientific explanation can never be certain - and conclude that science can never achieve truth. But this wrongly conflates truth with certainty. Again, antirealists rightly point out that a scientific explanation can never be ultimate - and conclude that science can never really explain anything. But this wrongly conflates explanation with ultimate explanation. The question is whether we can resist these mad-dog realist conflations and work out a defensible lap-dog version of realism.

Why can science not achieve certainty? Because science is based upon observation and experiment, yet its principles transcend observation and experiment in three different ways. First, the principles are general, while the results of observation and experiment are never completely general, however numerous they may be. This is the classical problem of induction. The favourite example is that observing lots of white swans cannot prove that all swans are white, since the next swan we come across might be a black one. (As you can see from this example, most philosophers of science come from the northern hemisphere; an unkind soul once joked that having black swans in it was Australia's chief contribution to the philosophy of science!)

The second way that theory transcends observation is precision. Scientific observation or measurement is always to some degree imprecise, while some scientific theories are mathematically precise. You cannot prove a precise theory from imprecise measurements.

The third way that theory transcends observation is in terms of observability itself. We can only observe observable things, while some scientific theories postulate unobservable things, events or processes. You cannot prove a theory about unobservables from observation.

For these three reasons, the observational or experimental methods of science cannot achieve certainty. But for all that, a general and precise theory about unobservable things might well be true. Yes, antirealists say, but is it ever reasonable to think that a scientific theory is true? To which I reply, of course it is. I shall come back to this.

What of the conflation of explanation with ultimate explanation? Little children often play the "explanation game." They ask a Why-question, and whatever answer the parent gives, they ask another Why-question about that answer. Whether children do this out of genuine curiosity, or just to get attention, I do not know. Back in the infancy of science Aristotle noted this potential infinite regress of explanation. We ask, "Why A?" and answer, "Because B." But then we can ask, "Why B?" And if we answer, "Because C" we can then ask, "Why C?" ... and so on, ad infinitum. The worry is: have we really explained A by citing B, if B cries out for explanation in its turn? 
Well, of course we have. As John Hospers put it:

There is an elementary but widely pervasive confusion on this point. It is said that unless an explanation has been given all the way down to the level of brute fact, no explanation has been given ... at all; e.g. unless we know why water expands on freezing ... we do not really know why our pipes burst. But surely this is not the case. Whether we know why water expands on freezing or not, we do know that it does so, and that it is because of its doing so that the pipes burst in cold weather. When we have asked why the pipes burst, the principle of the expansion of water does give an explanation. When we ask why water expands on freezing, we are asking another question. The first has been answered, whether we can answer the second or not. (Hospers 1946, 341, footnote)

Quite so. Why is there this "elementary but widespread confusion"? What lies behind it is the idea that an explanation should relieve our puzzlement, set our curiosity at rest. Scientific explanations do not do this - they do not relieve puzzlement, but rather relocate it. If we focus on the puzzlement and forget what it is about, we are bound to find scientific explanations wanting. Besides, puzzlement-relief is a very subjective business. What relieves one man's puzzlement may not relieve the next woman's. I dare say that more puzzlement has been relieved, down the ages, by the ritual incantation "God moves in mysterious ways" than by all the teachings of science. And I dare say that if puzzlement-relief is your aim, recourse to the whiskey bottle, or to some up-to-date equivalent, would work better than the study of science.

So, a genuine explanation need not be an ultimate explanation, which sets all curiosity at rest. Besides, what would an ultimate explanation be like? When children play the "explanation game," impatient parents often try to shut them up at some point by saying, "Because I say so." This is never a good answer to the child's last question. Yet both candidates for ultimate explanation resemble the impatient parent's "Because I say so." The secular candidate is "Because we say so" and the theological candidate is "Because God said so."

To illustrate the secular candidate, imagine the following dialogue between a small child and her parent:

Mummy, why is Uncle John unhappy?

Because he is a bachelor, and bachelors are unhappy.

But Mummy, why are bachelors unhappy?

Because they are unmarried. 
But Mummy, why are bachelors unmarried?

BECAUSE WE SAY SO - that's what the word means.

The secular candidate is Aristotle's idea of essences or of essential predication. It makes sense to ask why bachelors are unhappy (supposing that they are). But it makes little sense to ask why bachelors are unmarried. Why not? Because we say so, because we use or define the word "bachelor" just to mean an unmarried man.

The theological candidate for ultimacy is "Because God said so." Is this a better answer, as many people think? Darwin thought not. He drew attention to lots of strange biological phenomena that his theory of evolution could explain, about which the creationist could only say, "God said it should be so." Darwin complained that this was just "restating the facts in dignified language" rather than explaining them (Darwin 1859, 217; see also Musgrave 2010).

Still, restating the facts in dignified language is very popular and can take you far. John Polkinghorne used to be Professor of Physics at Oxford University. He accepted the idea that there are ultimate laws of physics, and noticed that a further question can be asked about them that physics cannot answer: "Why are the ultimate laws of physics what they are?" Physics cannot answer this question because a physical explanation of an ultimate law would traffic in deeper laws and show that it was not an ultimate law after all. Polkinghorne concluded that the only answer to the question "Why are the ultimate laws of physics what they are?" is "Because God said so." And he switched from being Professor of Physics to being Professor of Theology. This was a good move in one respect. His argument won him the Templeton Prize in Theology, which is worth a lot more than the Nobel Prize in Physics (See Polkinghorne 1994, 328; Musgrave 2009)!

Lap-dog realists like me resist the conflations of truth with certainty and of explanation with ultimate explanation. Yet these conflations run deep. Where do they come from? Perhaps they come from a religious or theological bent of mind. Religions traffic in certainties and ultimate explanations - or pretend to. And if we expect science to rival religion in these matters, we are bound to be disappointed. We are bound to fall back on the view that science does not provide genuine explanations at all. So there is an unholy alliance (forgive the pun) between religion and antirealism about science.

This unholy alliance was first forged in the sixteenth century out of the clash between science and religion. The Copernican theory that the earth moves clashed with certain biblical passages that, literally interpreted, said or implied that the earth does not move. Cardinal Robert Bellarmine, member of the Inquisition, who later was made a saint, found a way to dissolve the contradiction. Bellarmine was an acute thinker. He saw that a false 
theory might make nothing but true predictions, might "save the observable phenomena" as the ancients put it. He granted that Copernican theory "saved the phenomena" but denied that this showed it to be true. He advised the Copernicans to stop saying that their theory was true, and say instead only that it saved the phenomena, that the phenomena were as if it were true. As he put it, "This has no danger in it, and it suffices for mathematicians" (Letter to Foscarini, April 1615, reprinted in Santillana, 1955, 98-100).

Pope Urban VIII agreed and went further. He challenged Galileo to show not just that the Copernican theory saved the phenomena, but that the phenomena could be saved in no other way, that an omnipotent God could not have fixed things so that it was merely as if the earth moved about the sun, that the earth must move about the sun. In other words, he challenged Galileo to show that the Copernican theory was not just true but necessarily and ultimately true. Poor Galileo could not do this. He did propose his famously mistaken theory of the tides, describing them as "physical effects whose causes can perhaps be assigned no other way" than by supposing the earth to move (Galilei 1632). But at the end of his great Dialogue on the Two Chief World Systems of 1632, Galileo gave up. His character Simplicio, so far presented as the idiot Aristotelian, reiterates the pope's argument that God could have produced the tides in the oceans in some other way than by moving the earth and that "it would be excessive boldness for anyone to limit and restrict the Divine power and wisdom to some particular fancy of his own." Galileo's spokesman Salviati is stumped by what he calls this "admirable and angelic doctrine," and the Dialogue ends. Despite this, it got Galileo into trouble. Bellarmine had ordered him not to teach or defend the truth of the Copernican system and he had evidently disobeyed the order. Galileo was summoned before the Inquisition, forced to recant his teachings, placed under house arrest for the rest of his life, and forbidden to have visitors or to publish anything further.

Thus was antirealism about science invented by Bellarmine and Pope Urban VIII to dissolve the clash between Copernican science and their religion. A more amusing example of the same line of thinking came in the nineteenth century, when geologists were amassing huge bodies of evidence for the great antiquity of the earth, and when the discovery of fossils of extinct creatures fuelled evolutionary speculations. Philip Gosse was a famous naturalist and explorer, the author of forty books, the David Attenborough of his age. He was also a biblical fundamentalist who thought that the earth and all the creatures on it were specially created a few thousand years ago. Gosse agonized for years about the clash between his science and his religion. Then he hit upon a brilliant solution. In 1857, two years before Darwin's Origin of Species, Gosse published Omphalos: An Attempt to Untie the Geological Knot. "Omphalos" is Greek for belly button. Gosse's book begins with an erudite 
discussion of whether Adam and Eve had belly buttons. Think about it-it is a good question for a creationist! Gosse soberly concludes that Adam and Eve probably did have belly buttons. He soberly concludes, in other words, that God created them as if they had been born of women and were not the first people. It is the same, Gosse argued, with the rocks. God created them a few thousand years ago bearing all the marks of great age including the fossils, created them as if the teachings of geology and evolution were true. Similarly, God created trees with growth rings in them, crocodiles with fully-formed teeth in their jaws, and so on.

Philip Gosse's son Edmund describes what happened:

Never was a book cast upon the waters with greater anticipations of success ... My Father lived in a fever of suspense, waiting for the tremendous issue. This "Omphalos" of his ... was to fling geology into the arms of Scripture, and make the lion eat grass with the lamb. ... He offered it, with a glowing gesture, to atheists and Christians alike. ... But, alas! Atheists and Christians alike looked at it, and laughed, and threw it away. (Gosse 1907, 105)

Why did the geologists laugh at Gosse's hypothesis? They had not a scrap of geological evidence against it. "God created the earth as if geology were true" is evidentially equivalent with geology.

For the most extreme example of this kind of thinking, we must jump back in time to a philosopher, to George Berkeley, Anglican Bishop of Cloyne. Berkeley was a more radical thinker than most antirealists. He did not just dispute the truth of some particular scientific theory. He thought that all science was false. More radically still, he thought that our commonsense belief in external objects, out of which the sciences grow, is also false. Common sense posits external objects to explain regularities in our experience. I see a tree, I shut my eyes for a moment, and when I open them again I see the tree again. Why? Common sense answers that there is a tree out there, existing independently of me, and somehow causing my tree-experiences. Berkeley says this is wrong. There is no tree. Reality is entirely spiritual. Reality consists of finite spirits, like you and me, and an infinite spirit, God. Of course, we finite spirits have tree-experiences. But our tree-experiences are not caused by trees. Rather, they are plonked directly into our minds by God. It is just that God plonks tree-experiences into our minds as if our belief in trees were true.

Berkeley's philosophy is mad. Yet I have a love/hate relationship with it. I love it because it reduces to absurdity the antirealist lines of thinking that I hate. Science grows out of common sense, and no sharp line can be drawn between them. Thus it is hard to avoid slipping upward from realism about common sense to realism about science. But slippery slopes run both ways. 
If you deny scientific realism you will find it hard to avoid slipping down into Berkeley's denial of commonsense realism as well.

So Bellarmine said that God produces astronomical phenomena as if Copernican theory were true, and Gosse said that God produces geological phenomena as if geology were true, and Berkeley went the whole hog and said that God produces all phenomena as if common sense and science were true. It is no accident that in all these cases God gets into the picture. Bellarmine, Berkeley, and Gosse invented antirealism about science to dissolve clashes between science and religion. But the religious dimension is not essential. Instead of saying that God produces phenomena as if some theory were true, we can say that the phenomena just are as if that theory were true. So, we can form a theological surrealist transform of any theory $\mathrm{T}$ by saying, "God produces phenomena as if $\mathrm{T}$ were true" $\left(\mathrm{T}^{\mathrm{G}}\right)$ and we can form a secular surrealist transform of it by saying, "The phenomena are as if $\mathrm{T}$ were true" $\left(\mathrm{T}^{*}\right)$. Here "surrealism" is short for "surrogate realism." A theory and its surrealist transforms are empirically or observationally equivalent. No observation or experiment can decide between them. If we are strict empiricists for whom only evidence should determine theory-choice, there is nothing to choose between them and they are equally good theories.

But we should not be strict empiricists. There is a world of difference between $\mathrm{T}, \mathrm{T}^{\mathrm{G}}$ and $\mathrm{T}^{*}$ from an explanatory point of view. We may assume that the scientific theory $\mathrm{T}$ we started with explains its phenomena somehow. The theological surrealist transform of $\mathrm{T}\left(\mathrm{T}^{\mathrm{G}}\right)$ gives an all-purpose theological explanation of those same phenomena, namely "God said so." The secular surrealist transform of $\mathrm{T}\left(\mathrm{T}^{*}\right)$ gives no explanation of the phenomena at all.

Better the all-purpose theological explanation than no explanation at all. The trouble is that we poor humans cannot understand that explanation and are not meant to understand it. God plonks tree-experiences into our minds as if there were trees. How does She do that? How does divine causality operate? We have no idea and we are not meant to have any idea. We are just meant to comfort ourselves with the thought that God is omnipotent and can do anything.

Many thought God the weak link in Berkeley's system and removed Her from it. Berkeley minus God is secular surrealism, or as it is more usually called, "phenomenalism." This view is remarkably popular among philosophers - and scientists, too, for that matter. The great philosopher-physicist Ernst Mach agreed with Berkeley that the universe consists entirely of sensations. Mach had no explanation for why sensations of trees occur in a regular fashion. Trees do not explain it, and neither does God. Regularities in our experience are for Mach the ultimate inexplicable laws of nature.

Phenomenalism also became the rage among philosophers obsessed with 
problems about meaning. In the twentieth century all the best journals of so-called "analytic philosophy" were full of learned articles devoted to the project of "translating" statements about external objects into statements about actual and possible sense-experiences. I once wrote that Berkeley denied the existence of external objects. The reviewer of my book in Mind, the leading British philosophy journal, described this as an "egregious error" (Dancy 1994, 215). No, Berkeley did not deny the existence of trees, he just told us what we "really mean" when we assert their existence. What we "really mean" when we say that the tree continues to exist when we shut our eyes is that we will have more tree-experiences if we open our eyes. Well, that is not what I mean when I say that the tree continues to exist when I shut my eyes.

Getting back to antirealism about science, Bellarmine's view became remarkably popular. Its leading defender in the nineteenth century was the great philosopher-scientist Pierre Duhem, who, like his hero Bellarmine, was a devout Catholic. Its leading contemporary advocate is Bas van Fraassen, who as it happens is a late convert to Catholicism. Van Fraassen calls his position "constructive empiricism." A scientific theory is an intellectual tool or instrument for making predictions - or as van Fraassen's slogan puts it, "The name of the [scientific] game is saving the phenomena" (van Fraassen 1980, 93). A theory is a perfectly good theory if it makes nothing but true predictions, if it is empirically adequate. Of course, a false theory might be empirically adequate. Never mind, "a theory need not be true to be good" and science should aim for empirical adequacy rather than truth (van Fraassen 1980,10). Science should never claim that a theory is true, only that it is empirically adequate, that the phenomena are as if it were true. We should be strict empiricists and admit that there is nothing to choose between empirically equivalent theories.

The famous economist Milton Friedman defended the same view in his seminal piece, "The Methodology of Positive Economics." Friedman agreed that a scientific hypothesis need not be true to be good. Indeed, he seemed to go further and claim that the less true a hypothesis is, the better:

Truly important and significant hypotheses will be found to have "assumptions" that are widely inaccurate descriptive representations of reality, and, in general, the more significant the theory, the more unrealistic the assumptions. (Friedman 1953, 14; see also Musgrave 1981)

Nancy Cartwright said similar things about the laws of physics in her famous book How the Laws of Physics Lie: "The fundamental laws of physics do not describe true facts about reality. The fundamental laws of physics ... are simply false" (Cartwright 1983, 54-55; see also Musgrave 1995). 
Then there is Kyle Stanford, the recently elected President of the Philosophy of Science Association. He made his name by resurrecting Pope Urban VIII's argument, rechristening it "the argument from the unthought-of alternative," and claiming that it is fatal to scientific realism (Stanford 2006). Pope Urban VIII does not figure in Stanford's extensive bibliographies-but I dare say that he is resting safe in heaven without the benefit of a footnote from Professor Stanford. The pope's argument is fatal to mad-dog dogmatic realism; it is not fatal to the lap-dog critical realism that I defend.

I could multiply further examples - but time is short. Instead I will next argue that antirealism is a human chauvinistic philosophy that is at odds with some of the basic teachings of science. If science is to be believed, what human beings happen to be able to observe is an outcome of our particular evolutionary history. Other critters have different sensory systems and can observe things that we cannot. Even among humans, what can be observed varies; after all, some of us are short-sighted or colour-blind. Moreover, what we can observe shifts over time and with technology. People can see things wearing their glasses that they cannot see with the naked eye. Once we allow glasses in, why not telescopes or microscopes or electron microscopes, or any of the many other fancy detection devices that scientists have invented? The observable/unobservable distinction is vague, species-specific and shifting. And yet, idealists and antirealists give it crucial philosophical significance.

The idealists or positivists say, following Berkeley, say that the only things that exist are those that humans happen to be able to observe. Why should we accept that? Dogs and cats can hear or smell things we cannot. Should we deny that ultraviolet light exists, just because we cannot see it (though bees can)? Should we deny that atoms exist, just because they are too small for us to see with the naked eye?

Van Fraassen insists that he is no positivist: he concedes that unobservables exist. Yet he gives the observable/unobservable distinction crucial epistemological significance. We humans should only think true statements about what we can observe. We should not think true any statement about things we cannot observe. Such statements should only be accepted as empirically adequate, not as true. Van Fraassen also says, rightly, that it is up to science to tell us what is observable by humans and what is not. But now consider a scientific statement of the form "So-and-so's are unobservable by humans." This is not a statement about observables. So the consistent constructive empiricist cannot think it true. The consistent constructive empiricist cannot think it true that anything is unobservable by humans, contrary to what van Fraassen maintained. Since I pointed out this contradiction, a literature has grown up trying to extricate constructive empiricism from it- - but I do not have time to canvas that now.

Instead, let us go back to the beginning. I have said, more than once, 
that if science is to be believed, such and such is the case. But is science to be believed? Ought we to believe things that are uncertain, things that we cannot prove to be true? Well, of course we ought. We do it all the time, and we are perfectly reasonable to do so.

Notoriously, the term "belief" is ambiguous. It can refer to the content of the belief, the proposition believed, as when we say that two different people may have one and the same belief. Or it can refer to the mental act or state of believing something. This ambiguity carries over to the question of whether a belief is reasonable or justified. When we speak of justifying or giving a reason for a belief, do we mean justifying or giving a reason for the belief-content or for the belief-act? Obviously, we mean the latter. After all, one person might have a good reason for believing something, and somebody else might believe the same thing for no good reason at all. We deem the first belief (believing) reasonable and the second belief (believing) unreasonable. Yet the belief (belief-content) is exactly the same.

Despite these platitudes, a malign assumption dominates discussions of these matters. The assumption is that a reason for believing a proposition must be a reason for the proposition believed. This assumption seems self-evident. After all, to believe something is to think it true or more likely true than false. So a reason for believing something must show that what is believed is true or more likely true than false - must it not?

Still, the obvious question arises of what a reason for a proposition might be. The answer is equally obvious: logic tells us that. A conclusive reason for a proposition is another proposition that logically entails it. And an inconclusive reason for a proposition is another proposition that entails that it is more likely true than false. (We need an inductive logic to make good this second idea.) Suppose we accept that logic tells us what reasons for propositions are. Then we will end up with what I call logomania, the view that only logical reasoning can provide us with a reason to believe anything. And logomania combined with a familiar skeptical point will result in total irrationalism, the view that no belief (believing) is reasonable.

The mere existence of a proposition that entails something that you believe cannot provide you with a reason for your belief. Obviously, you must believe that other proposition. But inferring something from something else that you do not reasonably believe cannot provide you with a reason for your belief either. Obviously, you must reasonably believe that other proposition. So we end up with the logomaniac view that the only reason for believing something is that you have inferred it from some other belief for which you have reason.

But now, as skeptics down the ages have tirelessly pointed out, an infinite regress of reasons looms. Since nobody can complete an infinite chain of reasons for what they believe, everybody must start from non-inferential 
beliefs. But logomania means that non-inferential beliefs are unreasonable. From this it follows that all beliefs are unreasonable. If we are to avoid total irrationalism, we must reject logomania. We must think that some non-inferential beliefs are reasonable beliefs. And we must think that the reasons for them are reasons for the believings, not for the propositions believed.

The two prime sources of non-inferential beliefs are, of course, sense-experience and testimony. Plain folk, asked why they believe things, often invoke sense-experience or testimony as the answer. "Why do you believe that the cat is on the mat?" "Because I see her there." "Why do you believe that Everest is the tallest mountain?" "Because Granny told me so." The answers here invoke the causes and the reasons for acts of believing. Of course, for a logomaniac there are no reasons here at all; seeing the cat or listening to Granny are not propositions, and so cannot be reasons for propositions. But logomania is mistaken, as we have seen.

What goes for beliefs acquired from sense-experience and testimony may go for other beliefs as well. They, too, may be non-inferential, in the sense that they are not brought about by inferring them from other beliefs. And they, too, may be reasonable beliefs, but the reasons for them are reasons for the believings, not for the propositions believed. That a hypothesis has best withstood serious criticism is a reason for believing it. But it is not a reason for the hypothesis itself; it does not show that the hypothesis is true or more likely true than not. That is how Karl Popper solved the problem of induction, and claimed that inductive logic is a myth. Again, that a hypothesis provides the best available explanation of some phenomena is a reason for believing it, but it is not a reason for the hypothesis itself. Critics of Popper, and of inference to the best explanation, all presuppose logomania - or so I have argued.

Can it be so simple? A hypothesis might survive a critical discussion, or provide the best explanation of something, and yet still be false. Can it ever be reasonable to believe a falsehood, as I seem to be saying? Well, of course it can. To be sure, if we find out that what we reasonably believe is false, it is no longer reasonable to believe it. But what we do and should say in such cases is that what we reasonably believed was wrong - not that we were wrong or unreasonable to have believed it.

I began this abstruse discussion by asking, "Is science ever to be believed?" My answer should by now be obvious. Of course it is. In the sciences we have our best epistemic engine. It is not an infallible engine. Its best-tested results may yet be overthrown. Still, we ought to believe them, tentatively, just as we ought to believe some basic teachings of common sense, out of which the sciences have grown. Away with all that antirealist philosophy!

Oops-perhaps I am a mad dog realist after all. 


\author{
Alan Musgrave \\ Department of Philosophy \\ University of Otago \\ PO Box 56 \\ Dunedin 9054 \\ New Zealand \\ alan.musgrave@otago.ac.nz
}

\title{
REFERENCES
}

Cartwright, Nancy. 1983. How the Laws of Physics Lie. Oxford: Oxford University Press.

Dancy, Jonathan. 1994. Review of Common Sense, Science and Scepticism: A Historical Introduction to the Theory of Knowledge, by Alan Musgrave. Mind, 103(410): 214-216.

Darwin, Charles. 1859. On the Origin of Species by Means of Natural Selection. 1st ed. London: John Murray.

de Santillana, Georgio. 1955. The Crime of Galileo. London, Heinemann.

Friedman, Milton. 1953. The Methodology of Positive Economics. In Essays in positive economics, 3-43. Chicago: University of Chicago Press.

Galileo, Galilei. 1632. Dialogue Concerning the Two Chief World Systems-Ptolemaic and Copernican. Translated by Stillman Drake. Berkeley and Los Angeles: University of California Press 1962.

Gosse, Edmund. 1907. Father and Son. London: William Heineman. Reprint, London: Penguin Books, 1989.

Hospers, John. 1946. On Explanation. Journal of Philosophy 43(13): 337-356.

Musgrave, Alan E. 1981. Unreal Assumptions in Economic Theory. Kyklos, 34: 377-387. Reprinted in Bruce Caldwell, ed. 1984. Appraisal and Criticism in Economics: A Book of Readings, 234-244. London, Allen \& Unwin and in Musgrave 1999, 158-161.

Musgrave, Alan E. 2009. "Are Theological Notions Explanatory? In Secular Sermons: Essays on Science and Philosophy, 197-201. Dunedin: Otago University Press. Originally published in 1993.

Musgrave, Alan E. 1995. Realism and Idealization (Metaphysical Objections to Scientific Realism). In The Problem of Rationality in Science and Its Philosophy: On Popper vs. Polanyi, the Polish Conferences 1988-89, ed. J. Misiek, 143-66. Dordrecht and Boston: Kluwer Academic Publishers. Reprinted in Musgrave 1999, 131-53.

Musgrave, Alan E. 1999. Essays on Realism and Rationalism. Amsterdam: Rodopi.

Musgrave, Alan E. 2010. Darwin's Life and Method. In Aspects of Darwin: A New Zealand Celebration, ed. D. Galloway and J. Timmins, 20-35. Dunedin: Friends of the Knox College Library.

Polkinghorne, John. 1994. Theological notions of creativity and divine causality. In Science and Theology: Questions at the Interface, eds. M. Rae, H. Regan 
A. Musgrave

and J. Stenhouse, 225-237. Edinburgh: T \& T. Clark.

Stanford, P. K. 2006. Exceeding Our Grasp: Science, History, and the Problem of Unconceived Alternatives. Oxford: Oxford University Press.

Van Fraassen, Bas. C. 1980. The Scientific Image. Oxford: Clarendon Press 